\title{
METHODS OF SEPARATING SOIL CARBON POOLS AFFECT THE CHEMISTRY AND TURNOVER TIME OF ISOLATED FRACTIONS
}

\author{
Cristina Castanha ${ }^{1} \bullet$ Susan Trumbore $^{2} \cdot$ Ronald Amundson $^{3}$
}

\begin{abstract}
A variety of physical and chemical techniques are used to fractionate soil organic matter, but detailed comparisons of the different approaches and tests of how separation methods influence the properties of isolated organic matter pools are lacking. In this case study based on A horizon samples of 2 California coniferous forests soils, we 1) evaluate the effects of root removal and ultrasonic dispersion on the properties of the $<2 \mathrm{~g} \mathrm{~cm}^{-3}$ light fraction and 2) compare the properties of fractions obtained by sequential density separations of ultrasonically treated soil with those obtained by density followed by acid/base hydrolysis (Trumbore et al. 1996).
\end{abstract}

A root-removal effort based on hand-picking visible roots reduced the radiocarbon content and increased the estimated turnover time of the light fraction by roughly $12 \%$. Root-removal protocols that vary between investigators thus can potentially confound variability in carbon cycling for this fraction caused by environmental factors, such as climate. Ultrasonic dispersion did not have a clear effect on the light fraction $\mathrm{C}$ and $\mathrm{N}$ content or isotopic signature, but led to a decrease in the $\% \mathrm{C}$ and $\mathrm{C} / \mathrm{N}$ of the recovered heavy fractions, and losses of $12-19 \%$ of the total soil $\mathrm{C}$ to the sodium metatungstate density solution.

Sequentially isolated density fractions clearly differed in mineralogy and organic matter chemistry, but natural-abundance ${ }^{14} \mathrm{C}$ analyses indicated that distinct mineral phases did not correspond to unique C-turnover pools. Density fractions containing kaolinite group minerals alone and in combination with hydroxy-interlayered vermiculite were found to harbor both fast and slow cycling carbon. In contrast, severe chemical treatment isolated a carbon pool with the lowest overall ${ }^{14} \mathrm{C}$ content and longest inferred mean turnover time. Overall, our results show that care must be taken when relying on physical (density) separation to isolate soil fractions with different dynamics, as the details of treatment will influence the results.

\section{INTRODUCTION}

The measurement of radiocarbon in soil organic matter has greatly expanded our ability to quantitatively constrain rates of soil carbon cycling (O'Brien and Stout 1978; Goh et al. 1984; Trumbore et al. 1989; Amundson et al. 1998; Gaudinski et al. 2000; Trumbore 2000; Swanston et al. 2005). Soil organic matter is not a homogeneous pool but consists of components with turnover times ranging from years to many millennia. ${ }^{14} \mathrm{C}$ measurements of bulk soil integrate across these components and can therefore be misleading as a measure of how fast the organic matter will respond to a perturbation (Trumbore 2000). For example, while the residence time of bulk soil organic matter sampled in the 1950s may be consistent with carbon residence times of hundred to thousands of years, a time series of samples taken at the same site demonstrates rapid uptake of bomb ${ }^{14} \mathrm{C}$ produced in the early 1960s (Trumbore et al. 1996). Recognition that bulk soil ${ }^{14} \mathrm{C}$ measurements offer little insight into soil organic matter dynamics has led to a growing array of chemical and physical techniques that attempt to reliably partition bulk soil into operationally defined "fractions" with different characteristic carbon residence times (e.g. Balesdent 1987; Golchin et al. 1994; Trumbore and Zheng 1996; Shang and Tiessen 2001; Baisden et al. 2002; Masiello et al. 2004).

Soil organic matter fractionation procedures fall into broad categories such as physical methods, based on particle size, density, or degree of aggregation, and chemical methods, based on solubility in water, acids, bases, solvents, or salt solutions. Density differences have routinely been used to separate soil fractions with varying proportions of organic matter (Monnier et al. 1962; Greenland and Ford 1964; Sollins et al. 1983; Christensen 1992; Swift 1996; Shang and Tiessen 1998; Six et

\footnotetext{
'Lawrence Berkeley National Lab, 1 Cyclotron Road, Mail Stop 70A-4418, Berkeley, California 94720, USA.

Corresponding author. Email: ccastanha@lbl.gov.

${ }^{2}$ Physical Sciences Research Facility, University of California, Irvine, California 92697-3100, USA.

${ }^{3}$ Ecosystem Sciences, 137 Mulford Hall, University of California, Berkeley, California 94720-3114, USA.
} 
al. 2001). Organic matter in the low-density fractions (usually $<1.6-2 \mathrm{~g} \mathrm{~cm}^{-3}$ ) includes components of very different ages, ranging from slightly altered residues of roots and leaves, to charcoal fragments, to hydromorphic precipitates (humic materials). Further, depending on how fast aggregates themselves form and persist, the low-density organic matter trapped in soil aggregates should be older than that found in inter-aggregate spaces (Rasmussen et al. 2005; Ewing et al. 2006). Organic matter in the heavy fraction (usually $>2 \mathrm{~g} \mathrm{~cm}^{-3}$ ) is more directly associated with mineral surfaces, for example, via ligand exchange, cation bridging, and hydrogen bonds. These different mechanisms of soil organic matter (SOM) stabilization may in turn have different characteristic turnover times, so that the dense fraction also includes components of very different ages. Subjecting the heavy fractions to acid/base hydrolysis leaves a ${ }^{14} \mathrm{C}$-depleted organic matter residue (Trumbore and Zheng 1996) that generally matches the century-to-millenial cycling "passive pool" of soil carbon cycling models (Parton et al. 1987; Jenkinson et al. 1990). While they do isolate a much older organic matter fraction (Paul et al. 2001, 2006), such chemical methods have been criticized, however, out of concern that they lead to random cleavage of native compounds followed by repolymerization of artificial compounds (Olk and Gregorich 2006).

The success of different operational methods in separating carbon into pools with distinct residence times varies (e.g. Trumbore and Zheng 1996; Six et al. 2000; Baisden et al. 2002; Krull et al. 2006; Sollins et al. 2006; Basile-Doelsch et al. 2007), and depends to some degree on the soil characteristics and sample pretreatment. Here, we compare the effects of root removal, sonication, and density versus chemical fractionation on the residence times of organic matter fractions obtained from $\mathrm{A}$ horizons of 2 coniferous forest soils sampled along an elevation gradient in the western Sierra Nevada, California, USA.

${ }^{14} \mathrm{C}$ studies frequently rely on air-dried soils, for which separation of live and dead roots is not feasible. Yet in theory, only dead roots belong to the soil organic matter pool; living roots belong to the biomass pool. Prior work (Gaudinski et al. 2000, 2001) has indicated that the mean age of carbon in both live and dead fine root biomass is similar and has higher ${ }^{14} \mathrm{C}$ signature than most other components of the low-density fraction. Therefore, the ${ }^{14} \mathrm{C}$ content of the light fraction should be less affected by the separation of live and dead roots-a time-consuming and subjective procedurethan by the overall degree of root removal. A modest but consistent root-removal protocol may suffice to make light fraction residence time estimates across environmental gradients more reproducible and comparable. Accordingly, our first goal was to measure the effect of an easily achievable root-removal effort on the ${ }^{14} \mathrm{C}$ content of the $<2 \mathrm{~g} \mathrm{~cm}^{-3}$ (light) fraction.

Our second goal was to compare the ${ }^{14} \mathrm{C}$ content and $\mathrm{C} / \mathrm{N}$ ratio of soil organic matter fractions obtained by a density separation of shaken soil followed by acid/base hydrolysis of the heavy fraction (Trumbore and Zheng 1996; Trumbore et al. 1996) to fractions obtained by sequential density separations of ultrasonically treated soil (Basile-Doelsch et al. 2007). The first method (density/ hydrolysis) is designed to separate a mineral-free light fraction, a chemically labile (hydrolyzable) mineral-associated fraction, and a chemically recalcitrant (nonhydrolyzable) mineral-associated fraction. The second method (sonication/density) is designed to separate the entire light fraction (comprising both the mineral-free and mineral-occluded particulate material) and several heavy fractions characterized by distinct mineral species (e.g. kaolinite, quartz, and mica) and their associated organic matter. This comparison allows us to assess how ultrasonic dispersion energy affects the separation of light versus heavy fractions and if and how the chemical resistance of organic matter is associated with mineralogy. 


\section{SITE DESCRIPTION}

Our study is based on 2 A horizon samples from granitic soils, sampled in 1992 and initially analyzed as part of an elevation gradient study on the western slope of the Sierra Nevada, California (Trumbore et al. 1996; see Table 1). The Musick soil, a well-developed Ultic Haploxeralf, is located just below the permanent winter snowline where moderate mean annual temperature and precipitation values promote chemical weathering and the accumulation of kaolinite clay and iron oxides. The Shaver soil, a less-developed Pachic Xerumbrept, is located just above the permanent winter snowline, where snowmelt leaching dominates the soil hydrology, acting to retard the accumulation of clay, but promoting the production of 2:1 layered hydroxy-Al interlayered vermiculite in addition to 1:1 layered kaolins. (Dahlgren et al. 1997).

Table 1 Characteristics of the soils used in this study.

\begin{tabular}{|c|c|c|}
\hline & Musick & Shaver \\
\hline Classification & $\begin{array}{l}\text { Fine-loamy Ultic Haploxer- } \\
\text { alf }\end{array}$ & $\begin{array}{l}\text { Coarse-loamy Pachic Xe- } \\
\text { rumbrept }\end{array}$ \\
\hline Dominant plant species & $\begin{array}{l}\text { Ponderosa pine, Incense ce- } \\
\text { dar (Libocedrus decurrens), } \\
\text { Manzanita (Arctostaphylos } \\
\text { manzanita) }\end{array}$ & $\begin{array}{l}\text { White fir (Abies concolor), } \\
\text { Ponderosa pine (Pinus pon- } \\
\text { derosa), Sugar pine (Pinus } \\
\text { lambertiana) }\end{array}$ \\
\hline Elevation (m) & 1240 & 1780 \\
\hline Mean annual temperature $\left({ }^{\circ} \mathrm{C}\right)$ & 11.7 & 8.9 \\
\hline Mean annual precipitation $(\mathrm{cm})$ & 94 & 102 \\
\hline Horizon and depth & $\mathrm{A} 1,0-7 \mathrm{~cm}$ & $\mathrm{~A} 2,5-10 \mathrm{~cm}$ \\
\hline Texture (\% sand, silt, clay) & $46,34,20$ (loam) & $68,25,7$ (sandy loam) \\
\hline Structure & Moderate, medium, granular & Weak, fine, granular \\
\hline Roots $^{\mathrm{a}}$ & $\begin{array}{l}\text { Common very fine; few fine } \\
\text { and coarse }\end{array}$ & $\begin{array}{l}\text { Common coarse; many very } \\
\text { fine, fine, and medium }\end{array}$ \\
\hline
\end{tabular}

${ }^{a}$ In situ observation per unit of cross-sectional area through the horizon (Schoeneberger et al. 1998).

\section{METHODS}

Two fractionation protocols were applied. The first was carried out by Tumbore et al. (1996) and the second follows the method of Basile-Doelsch et al. (2007).

\section{1) Soil Separation by Density Followed by Acid/Base Hydrolysis (Trumbore and Zheng 1996; Trumbore et al. 1996)}

Freshly collected soils were sieved to $<2 \mathrm{~mm}$ and air-dried. Following widely accepted standards, roots that fell through the 2-mm sieve were assumed to be part of the soil organic matter pool (Nelson and Sommers 1996). One $\sim 5$-g split per sample was placed in a 50-mL polypropylene tube. The

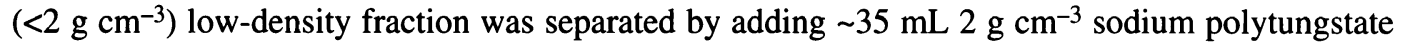
$\left(3 \mathrm{Na}_{2} \bullet\left(\mathrm{WO}_{4} \bullet 9 \mathrm{WO}_{3}\right) \cdot \mathrm{H}_{2} \mathrm{O}\right)$ solution, shaking to disperse, centrifuging to settle, decanting the floating material onto a prebaked quartz fiber filter, and repeating the sequence, up to 6 times, until no additional material was retrieved. No sonication was used, only shaking to redisperse the centrifuged residue. The low-density material on the filter was rinsed with $1 \mathrm{~L}$ of distilled water to remove residual salts, then dried.

The heavy fraction $\left(>2 \mathrm{~g} \mathrm{~cm}^{-3}\right)$ at the bottom of the tube was also rinsed with water, dried, weighed, and split for ${ }^{14} \mathrm{C}$ analysis and acid/base hydrolysis. For the hydrolysis procedure, tubes were filled with $0.5 \mathrm{~N} \mathrm{HCl}$, shaken repeatedly, then left to sit overnight, centrifuged, decanted, and rinsed 3 
times with distilled water. Base hydrolysis used $0.1 \mathrm{~N}$ sodium hydroxide $(\mathrm{NaOH})$-sodium pyrophosphate $\left(\mathrm{Na}_{4} \mathrm{P}_{2} \mathrm{O}_{7} \bullet 10 \mathrm{H}_{2} \mathrm{O}\right)$ solution. This was added to tubes, which then were shaken (to mix), left overnight, centrifuged, and rinsed 3 times with distilled water. Finally, $6 \mathrm{~N}$ hydrochloric acid $(\mathrm{HCl})$ was added, tubes were put on a heating block to reach $95^{\circ} \mathrm{C}$, left overnight, centrifuged, and the residue was rinsed at least 3 times with distilled water (Trumbore and Zheng 1996).

The ${ }^{14} \mathrm{C}$ analyses (described below) were conducted on single subsamples of the light, heavy, and acid/base residue fractions. The $\% \mathrm{C}$ was determined manometrically on purified $\mathrm{CO}_{2}$. The nitrogen content of the light and heavy fractions was determined using a Fisons NA-1500 analyzer.

\section{2) Sequential Density Separation of Ultrasonically Treated Soil (Basile-Doelsch et al. 2007)}

Subsamples of the archived 2-mm air-dried soils were split into four $\sim 5$-g aliquots using a precision splitter (ELE International, model CL-244, 7-mm slot riffle sampler). Roots, which may have been either live or dead at the time of sampling, were hand-picked out of each split for $10 \mathrm{~min}$ (after 10 min, the yield of additional fine roots decreased greatly). Roots and corresponding hand-picked soil samples were freeze-dried and weighed.

Four replicates of each soil sample were placed in 50-mL polypropylene tubes to which $30 \mathrm{~mL}$ of deionized water was added. Capped tubes were gently mixed by inverting 6 times and allowed to sit for at least $1 \mathrm{hr}$ to fully wet the sample. After this period, the tubes were mixed using a Vortex ${ }^{\circledR}$ mixer for $10 \mathrm{~s}$, immersed in an ice bath, and sonicated at $200 \mathrm{~W}$ for 3 min using a 350-W Branson ${ }^{\mathrm{TM}}$ sonicator with a $12.5-\mathrm{mm}$ probe immersed to $3 \mathrm{~cm}$ depth. Tubes were then shaken at $180 \mathrm{rpm}$ for $10 \mathrm{~min}$ and centrifuged at $20,000 \mathrm{~g}$ for $32 \mathrm{~min}$ to settle $1.05 \mathrm{~g} \mathrm{~cm}^{-3}$ and $0.2-\mu \mathrm{m}$-diameter spherical particles. The floating material, corresponding to the $0-1 \mathrm{~g} \mathrm{~cm}^{-3}$ fraction, was isolated by decanting.

Sequentially heavier fractions were extracted using sodium polytungstate (SPT) solution adjusted to successively higher densities between 2 and $3.2 \mathrm{~g} \mathrm{~cm}^{-3}$. At each step, $\sim 30 \mathrm{~mL}$ of density-adjusted solution was added to the centrifuge tubes, which were vortex-mixed to disengage the heavy fraction pellet from the bottom, shaken for $10 \mathrm{~min}$, sonicated for $45 \mathrm{~s}$, and centrifuged. The centrifuge time and speed was adjusted such that $0.2-\mu \mathrm{m}$-diameter spherical particles with a density $0.05 \mathrm{~g} \mathrm{~cm}^{-3}$ higher than the solution would settle to the bottom of the tube according to Stoke's law (reviewed by Christensen 1992). Following centrifugation, each floating fraction, and finally the $>3.2 \mathrm{~g} \mathrm{~cm}^{-3}$ fraction, was decanted into a clean 50-mL tube, diluted with enough water to allow them to settle, centrifuged, and rinsed 3 times with deionized water. All fractions were freeze-dried and weighed.

Two replicates of each density fraction, as well as the root and corresponding hand-picked bulk soil samples, were used for carbon and nitrogen analysis. Samples were ground to pass through a $200-\mu \mathrm{m}$ sieve, and stored in a dessicator for at least $24 \mathrm{hr}$ prior to being loaded into tin capsules, which were weighed, and then analyzed on a Europa 20/20 continuous-flow stable isotope ratio mass spectrometer located at the Center for Stable Isotope Biogeochemistry, University of California, Berkeley. The mass spectrometer was calibrated to NIST 1547 Peach Leaves $(45.5 \% \mathrm{C}$, $2.96 \% \mathrm{~N}$ ), which, labeled as unknowns, varied between 45.0 and $46.1 \% \mathrm{C}$, and between 2.92 and $2.99 \% \mathrm{~N}$ for all runs.

Two replicates from each density or root fraction were combined into single samples that were analyzed for ${ }^{14} \mathrm{C}$ as described below. The agreement between $\% \mathrm{C}$ obtained by manometric determination following sealed-tube combustion (corresponding to the Trumbore protocol) and by mass spectrometer (corresponding to the Basile protocol) was good $\left(\mathrm{C}_{\text {Sealed tube }}=\mathrm{C}_{\text {Mass Spec }} \times 0.92 ; R^{2}=0.98\right.$, $p<0.001, n=14$, residuals randomly distributed). 


\section{Radiocarbon Analyses}

Subsamples for ${ }^{14} \mathrm{C}$ analyses were weighed and sealed in evacuated quartz or Vycor ${ }^{\circledR}$ tubes with $0.5 \mathrm{~g} \mathrm{Cu}, 1 \mathrm{~g} \mathrm{CuO}$, and a strip of $\mathrm{Ag}$ foil (Boutton 1991) and combusted for $3 \mathrm{hr}$ at $875-900{ }^{\circ} \mathrm{C}$ (Minagawa et al. 1984). The evolved $\mathrm{CO}_{2}$ was cryogenically purified under vacuum then reduced to graphite on which the ${ }^{14} \mathrm{C}$ was determined at the Center for Accelerator Mass Spectrometry, Lawrence Livermore National Labs (CAMS). ${ }^{14} \mathrm{C}$ data are reported as $\Delta{ }^{14} \mathrm{C}$ :

$$
\Delta^{14} C=\left(\frac{{ }^{14} C /{ }^{12} C_{\text {sam }} \times e^{\lambda(1950-x)}}{{ }^{14} C /{ }^{12} C_{\text {std }}}-1\right) \times 1000
$$

which is the fractional deviation, in parts per thousand $\left(\%\right.$ ), of the ${ }^{14} \mathrm{C} /{ }^{12} \mathrm{C}$ ratio in the sample (corrected for the year, $x$, in which it was collected) from that of the internationally accepted ${ }^{14} \mathrm{C}$ dating standard (95\% of the activity of the NBS oxalic acid standard in AD 1950, corrected for decay of standard, and normalized to $\delta^{13} \mathrm{C}=-19 \%$ o with respect to PDB standard) (Stuiver and Polach 1977). The ${ }^{14} \mathrm{C} /{ }^{12} \mathrm{C}$ of the sample is corrected to a $\delta^{13} \mathrm{C}$ value of $-25 \%$ o to account for the assumption that plants discriminate twice as much against ${ }^{14} \mathrm{C}$ as they do against ${ }^{13} \mathrm{C}$. Samples were either analyzed in 1993 (Trumbore protocol) or 2002 (Basile protocol). We did not correct for the $\sim 1 \%$ o difference in $\Delta^{14} \mathrm{C}$ caused by radioactive decay of ${ }^{14} \mathrm{C}$ between 1993 and 2002 as this was small compared to overall measurement accuracy of $\sim 4 \%$.

\section{Turnover Time Calculation}

Carbon turnover times were calculated using a time-dependent steady-state box model described in detail elsewhere (Trumbore 1988; Gaudinski et al. 2000; Torn et al. 2002; Wang and Hsieh 2002). For each year, $y$ :

$$
\left(C_{y}\right) \times\left({ }^{14} C_{y}\right)=\left(C_{y-1}\right) \times\left({ }^{14} C_{y-1}\right) \times(1-k-\lambda)+I \times\left({ }^{14} \mathrm{Catm}_{(y-\text { lag }}\right)
$$

where, $C$ is the carbon inventory of a soil fraction (mass); ${ }^{14} \mathrm{C}$ is the ${ }^{14} \mathrm{C}$ value of a soil fraction $(\%)$; $k$ is the first-order decomposition constant for homogeneous $C$ pools (Rodhe 1992) (year ${ }^{-1}$ ); $\lambda$ is the ${ }^{14} \mathrm{C}$ decay constant $\left(1.21 \mathrm{E}-4\right.$ year $\left.{ }^{-1}\right) ; I$ is the annual carbon input (mass year ${ }^{-1}$ ); ${ }^{14} \mathrm{Catm}$ is the ${ }^{14} \mathrm{C}$ value of the atmosphere (Levin and Hesshaimer 2000); and lag is the average number of years that atmospheric carbon is retained in plant tissue before becoming part of the soil organic matter pool. At steady state, $C_{y}=C_{y-1}$ and $I=k C$, so Equation 2 can be divided by $C_{y}$ to obtain:

$$
{ }^{14} C_{y}=\left({ }^{14} \mathrm{Catm}_{(y-\text { lag })}\right) \times k+\left({ }^{14} C_{y-1} \times(1-k-\lambda)\right)
$$

The decomposition constant, $k$, or its inverse, the turnover time, $T$, is obtained by matching the modeled and measured ${ }^{14} \mathrm{C}$ values for the year in which the soil was sampled.

\section{Mineralogy}

One replicate from each mineral-rich fraction (including the acid/base hydrolysis residue) was ground to $<100 \mu \mathrm{m}$ and subjected to powder X-ray diffraction (Rigaku Geigerflex, $\mathrm{Cu} \mathrm{K \alpha}$ ). Diffraction intensity was recorded every $0.05^{\circ}$ for 2.5 seconds between 2 theta $3^{\circ}$ and $65^{\circ}$ by Theta software. The diffraction data of Brindley and Brown (1984) were used to identify mineral species. 


\section{RESULTS}

\section{Root Removal}

Fine roots ( $<2 \mathrm{~mm}$ diameter) represented $7-11 \%$ of the light fraction carbon and had ${ }^{14} \mathrm{C}$ values that were 100-200\%o higher than the remaining material (Table 3; and see Table 2 for a list of abbreviations used in all tables). For the Musick soil, turnover times were estimated to be 10-12 yr for roots versus 55-59 yr for the remaining light fraction. For the Shaver soil, the turnover times were 38-42 yr for roots and 88-104 yr for the remaining light fraction. Root removal increased estimated turnover time of the light fraction carbon by $\sim 12 \%$; i.e. $\sim 6 \mathrm{yr}$ for the Musick and $\sim 11 \mathrm{yr}$ for the Shaver soil.

Table 2 List of abbreviations and subscripts used in Tables 3-5.

\begin{tabular}{lll}
\hline Abbreviations: & $\mathrm{Mt}$ & proportion of total mass \\
& $\mathrm{Ct}$ & proportion of total carbon \\
Subscripts: & bulk & bulk soil \\
& root & removed roots \\
& $\mathrm{LF}$ & $<2 \mathrm{~g} \mathrm{~cm}^{-3}$ light fraction \\
& $\mathrm{HF}$ & $>2 \mathrm{~g} \mathrm{~cm}^{-3}$ heavy fraction \\
& hyd & hydrolyzable fraction \\
& res & acid/base residue fraction \\
& lost & dissolved lost fraction \\
\hline
\end{tabular}

Table 3 The effect of root removal on the proportion of total carbon $(\mathrm{Ct}), \Delta{ }^{14} \mathrm{C}$ content, and ${ }^{14} \mathrm{C}$-derived turnover times of the $<2 \mathrm{~g} \mathrm{~cm}^{-3}$ light fraction.

\begin{tabular}{|c|c|c|c|c|c|c|c|}
\hline \multirow[b]{2}{*}{ Soil } & \multirow[b]{2}{*}{ Fraction } & \multicolumn{2}{|c|}{$\mathrm{Ct}^{\mathrm{a}}$} & \multicolumn{2}{|c|}{$\Delta^{14} \mathrm{C}(\% \circ)$} & \multicolumn{2}{|c|}{ Turnover time $(\mathrm{yr})^{\mathrm{b}}$} \\
\hline & & mean & s.e. & & Error $^{c}$ & mid & range \\
\hline \multirow[t]{3}{*}{ Musick } & Roots & 0.07 & 0.02 & 354 & 5 & 11 & 1 \\
\hline & Hand-picked light fraction & 0.93 & 0.11 & 137 & 4 & 57 & 2 \\
\hline & Whole light fraction & 1 & 0.11 & 152 & 4 & 51 & 2 \\
\hline \multirow[t]{3}{*}{ Shaver } & Roots & 0.11 & 0.03 & 185 & 5 & 40 & 2 \\
\hline & Hand-picked light fraction & 0.89 & 0.10 & 84 & 4 & 96 & 8 \\
\hline & Whole light fraction & 1 & 0.10 & 95 & 4 & 85 & 7 \\
\hline
\end{tabular}

${ }^{\mathrm{a}} \mathrm{Ct}=$ proportion total carbon.

${ }^{\text {b }}$ To fit the Musick ${ }^{14} \mathrm{C}$ data to our model, it was necessary to assume an $11-y r$ lag time (Equations 2 and 3 ). The turnover times of the Shaver root and light fraction were not sensitive to lag time; the values shown span the results for lag times from 5 to $11 \mathrm{yr}$. The turnover times of the whole light fraction were derived from the corresponding ${ }^{14} \mathrm{C}$ values, which were calculated as the $\mathrm{Ct}$-weighted ${ }^{14} \mathrm{C}$ values of the root and hand-picked light fractions. The range of turnover times is based on the ${ }^{14} \mathrm{C}$ error.

${ }^{c}$ Analytical error reported by CAMS.

\section{Density/Hydrolysis Fractionation (Trumbore Protocol)}

The \% C values of the light fractions (Table 4) were lower than expected due to the presence of quartz fiber filter scrapings, which also led to a high proportion of the total mass in the low-density fraction, particularly for the Shaver soil. This did not affect the ${ }^{14} \mathrm{C}$ values, however. The light fractions were enriched by $56 \%$ (Musick) and $43 \%$ (Shaver) relative to the bulk soil, whereas the acid/ base residue fractions, which contained $14 \%$ (Shaver) to $25 \%$ (Musick) of the heavy fraction carbon, were noticeably ${ }^{14} \mathrm{C}$-depleted. X-ray diffraction (XRD) data show that quartz is the principal mineral phase in the acid/base residue, which also includes hornblende and feldspars (Figure 1). 
Table 4 Results of the separation by density followed by acid/base hydrolysis (density/hydrolysis fractionation). ${ }^{\mathrm{a}}$

\begin{tabular}{|c|c|c|c|c|c|}
\hline Soil & Fraction & Mt & $\mathrm{C}(\%)$ & $\mathrm{Ct}$ & $\Delta^{14} \mathrm{C}$ \\
\hline \multirow[t]{5}{*}{ Musick } & Measured bulk soil & & 3.9 & & 108 \\
\hline & Light fraction & 0.11 & 15.7 & 0.46 & 164 \\
\hline & Heavy fraction ${ }^{b}$ & 0.89 & 2.4 & 0.54 & 24 \\
\hline & Hydrolyzate & 0.23 & 6.8 & 0.41 & 44 \\
\hline & Residue & 0.65 & 0.8 & 0.13 & -40 \\
\hline \multirow[t]{5}{*}{ Shaver } & Measured bulk soil & & 1.5 & & 66 \\
\hline & Light fraction & 0.25 & 3.8 & 0.63 & 109 \\
\hline & Heavy fraction ${ }^{a}$ & 0.75 & 0.7 & 0.37 & 73 \\
\hline & Hydrolyzate $^{\mathrm{b}}$ & 0.14 & 3.4 & 0.32 & 99 \\
\hline & Residue & 0.61 & 0.1 & 0.05 & -87 \\
\hline
\end{tabular}

${ }^{\mathrm{a}} \mathrm{Mt}=$ proportion total mass and $\mathrm{Ct}=$ proportion total carbon.

${ }^{\mathrm{b}} \mathrm{The}^{\mathrm{Mt}} \mathrm{t}_{\mathrm{HF}}, \mathrm{Ct}_{\mathrm{HF}}$, and $\mathrm{Ct}_{\mathrm{LF}}$ values were calculated based on the measured $\% \mathrm{C}$ values of the bulk, $\mathrm{LF}$, and $\mathrm{HF}$ fractions and by assuming $\mathrm{Mt}_{\mathrm{HF}}+\mathrm{Mt}_{\mathrm{LF}}=1$.

${ }^{\mathrm{c}}$ By definition, $\mathrm{Mt}_{\mathrm{hyd}}=\mathrm{Mt}_{\mathrm{HF}}-\mathrm{Mt}_{\mathrm{res}}$ and $\mathrm{Ct}_{\text {hyd }}=\mathrm{Ct}_{\mathrm{HF}}-\mathrm{Ct}_{\mathrm{res}}$. Thus, $\% \mathrm{C}_{\text {hyd }}$ and ${ }^{14} \mathrm{C}_{\text {hyd }}$ were calculated as weighted differences of the corresponding values for heavy and residue fractions.

\section{Theta (degrees)}

\section{5}

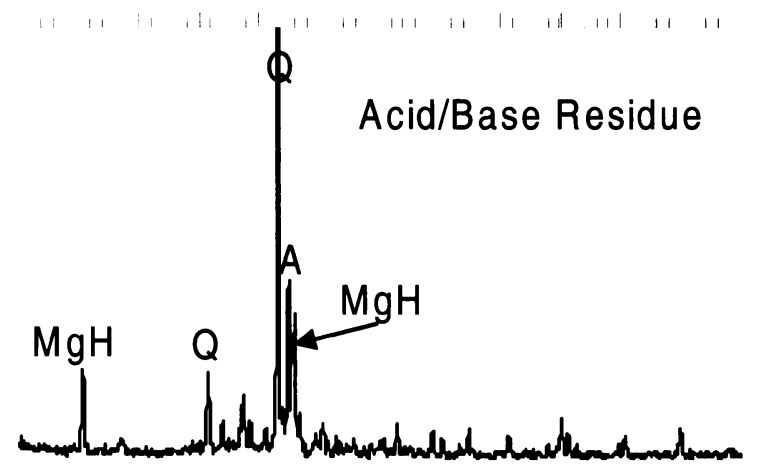

Figure 1 Powder X-ray diffraction spectrum for the acid/base residue of the Shaver soil (Musick spectrum is identical). Diagnostic peaks for quartz $(\mathrm{Q})$, anorthite $(\mathrm{A})$, and magnesiohornblende $(\mathrm{MgH})$ are labeled.

\section{Sonication/Density Fractionation (Basile Protocol)}

The mineral-free $<2 \mathrm{~g} \mathrm{~cm}^{-3}$ light fractions accounted for less than $10 \%$ of the soil mass but had $41 \%$ (Shaver) to $59 \%$ (Musick) of the soil carbon, which was ${ }^{14} \mathrm{C}$-enriched by $20 \%$ (Shaver) to $40 \%$ o (Musick) relative to the bulk soil (Table 5). The XRD data show that the principal mineral phases found in the 2-25, 2.5-2.6, 2.6-2.7, 2.7-3.2, and $>3.2 \mathrm{~g} \mathrm{~cm}^{-3}$ fractions of the Musick soil were the kaolin-type clays (halloysite and kaolinite), kaolin-type clays plus feldspars, quartz, mica, and hornblende, respectively. In addition to halloysite and kaolinite, the Shaver $2.2-2.5 \mathrm{~g} \mathrm{~cm}^{-3}$ fraction contained vermiculite and gibbsite (Figure 2). The $\% \mathrm{C}, \mathrm{C} / \mathrm{N}$, and ${ }^{14} \mathrm{C}$ values generally tended to decrease with density. The $2-2.2 \mathrm{~g} \mathrm{~cm}^{-3}$ fractions, with higher $\% \mathrm{C}$ but lower $\mathrm{C} / \mathrm{N}$ ratios than the 


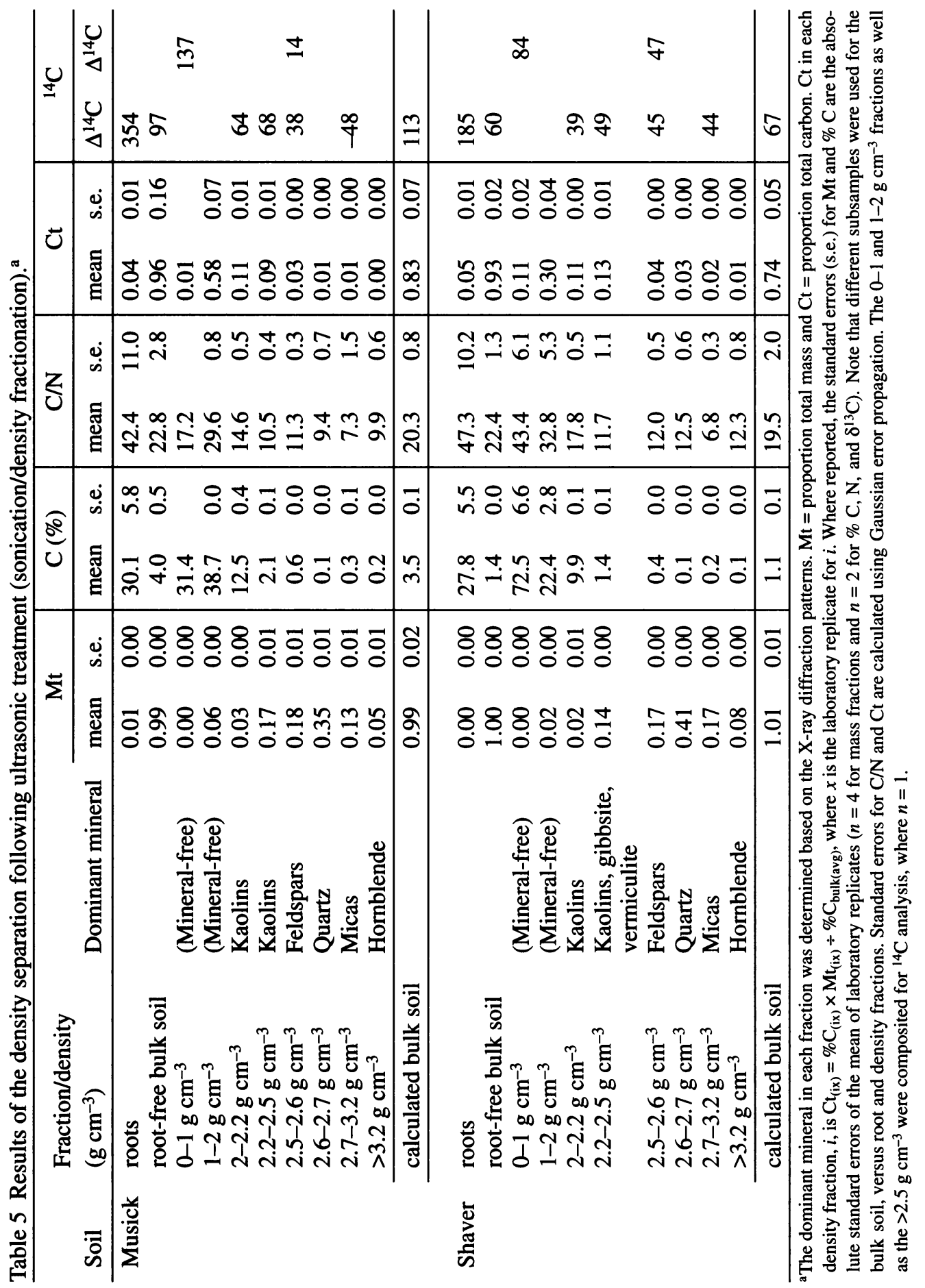


bulk soil, reflected a transition from mineral-free to mineral-associated organic matter. Most of the mineral-associated carbon was found in the $2-2.5 \mathrm{~g} \mathrm{~cm}^{-3}$ secondary mineral fractions. The quartzdominated fractions $\left(2.6-2.7 \mathrm{~g} \mathrm{~cm}^{-3}\right)$ had the lowest $\% \mathrm{C}$ values and $35-41 \%$ of the total soil mass. The mica-dominated fractions $\left(2.7-3.2 \mathrm{~g} \mathrm{~cm}^{-3}\right)$ had the lowest $\mathrm{C} / \mathrm{N}$ ratios and, in the case of the Musick soil, a ${ }^{14} \mathrm{C}$ content that was depleted by $-145 \%$ relative to the bulk soil. None of the density fractions captured a sizable homogeneous pool of ${ }^{14} \mathrm{C}$-depleted carbon, however; the mica-dominated Musick fraction only accounted for $1 \%$ of the total carbon. Among the mineral fractions, the ${ }^{14} \mathrm{C}$ content varied more for the Musick than the Shaver soil; the range between maximum and minimum $\Delta^{14} \mathrm{C}$ values was $185 \%$ for the former but only $45 \%$ o for the latter.

\section{Theta (degrees)}
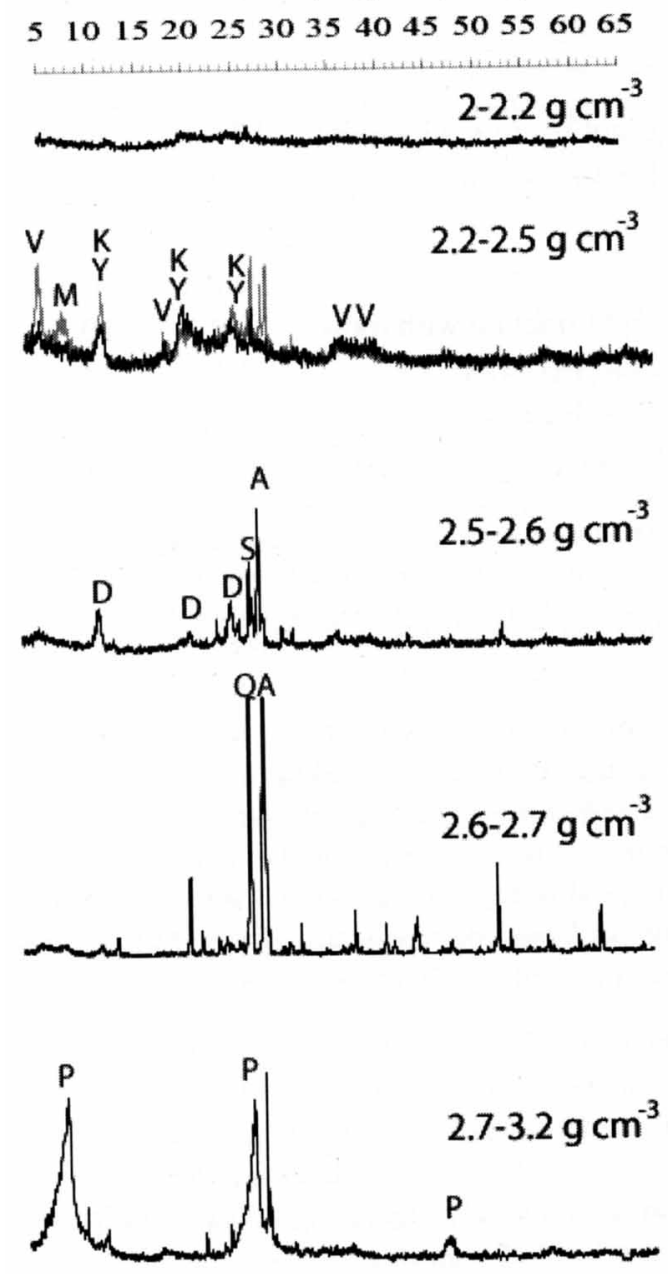

Figure 2 Powder X-ray diffraction spectra for density fractions, labeled in $\mathrm{g} \mathrm{cm}^{-3}$. Spectra are shown for the Musick soil only because spectra were identical for both soils with the exception of the $2.2-2.5 \mathrm{~g} \mathrm{~cm}^{-3}$ fraction, where the Shaver soil spectrum is in gray. Diagnostic peaks for halloysite $(Y)$, kaolinite $(\mathrm{K})$, vermiculite $(\mathrm{V})$, quartz $(\mathrm{Q})$, anorthite $(\mathrm{A})$, sanidine $(\mathrm{S})$, dickite $(\mathrm{D})$, phlogipite $(\mathrm{P})$, and magnesiohornblende $(\mathrm{MgH})$ are labeled.

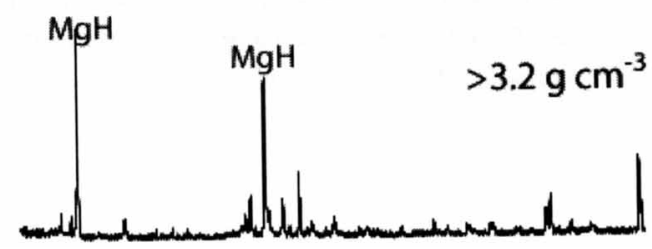




\section{Density Separation Preceded by Shaking (Trumbore Protocol) vs. Sonication (Basile Protocol)}

The results for light versus heavy fractions obtained after shaking versus sonication are summarized in Table 6. For the purposes of this comparison, all the light fraction values include roots (see details in Table 6 footnote).

Table 6 Comparison of the light vs. heavy fraction split obtained by shaking vs. sonication for bulk soil (roots included), light $\left(<2 \mathrm{~g} \mathrm{~cm}^{-3}\right)$, and heavy $\left(>2 \mathrm{~g} \mathrm{~cm}^{-3}\right)$ fractions.

\begin{tabular}{|c|c|c|c|c|c|c|}
\hline \multirow[b]{2}{*}{ Fraction } & \multicolumn{3}{|c|}{ Musick } & \multicolumn{3}{|c|}{ Shaver } \\
\hline & $\mathrm{C}(\%)$ & $\mathrm{C} / \mathrm{N}$ & $\Delta^{14} \mathrm{C}(\% o)$ & $\mathrm{C}(\%)$ & $\mathrm{C} / \mathrm{N}$ & $\Delta^{14} \mathrm{C}(\% o)$ \\
\hline \multirow[t]{2}{*}{ Bulk with roots ${ }^{a}$} & 3.9 & 21 & 108 & 1.5 & 23 & 66 \\
\hline & \multicolumn{6}{|c|}{ Density/hydrolysis separation (shaken up to 6 times) } \\
\hline Light fraction with roots & 15.7 & 30 & 164 & 3.8 & 31 & 109 \\
\hline \multirow[t]{2}{*}{ Heavy fraction } & 2.4 & 22 & 24 & 0.7 & 19 & 73 \\
\hline & \multicolumn{6}{|c|}{ Sonication/density separation ( $1300 \mathrm{~J}$ sonication per $\mathrm{g}$ soil solution) } \\
\hline Light fraction with roots ${ }^{b}$ & 37.9 & 30 & 152 & 26.0 & 36 & 95 \\
\hline Heavy fraction ${ }^{c}$ & 1.1 & 12 & 56 & 0.5 & 13 & 45 \\
\hline Dissolved fraction ${ }^{d}$ & & 26 & -16 & & 53 & 35 \\
\hline
\end{tabular}

${ }^{a}$ The Musick soil $\% \mathrm{C}_{\text {bulk }}$ and $\mathrm{C} / \mathrm{N}_{\text {bulk }}$ values were obtained from direct measurement of unpicked bulk samples $(n=4)$. The Shaver $\% \mathrm{C}_{\text {bulk }}$ and $\mathrm{C} / \mathrm{N}_{\text {bulk }}$ as well as the ${ }^{14} \mathrm{C}$ values for both soils are weighted sums of the separate root and hand-picked bulk samples ( $n=2$ for $\% \mathrm{C}$ and $\mathrm{N}, n=1$ for ${ }^{14} \mathrm{C}$ ).

${ }^{b}$ Light fraction values are weighted sums of the root, $0-1$, and $1-2 \mathrm{~g} \mathrm{~cm}^{-3}$ fractions.

${ }^{c}$ Heavy fraction values are weighted sums of the recovered mineral fractions and do not include losses.

${ }^{d}$ The lost fraction is the difference between the root, light, and heavy fractions and the bulk soil with roots.

Despite inconsistencies in the light fraction \% $\mathrm{C}$ values (caused by the presence of quartz fiber scrapings in the combusted sample), $\mathrm{C} / \mathrm{N}$ and ${ }^{14} \mathrm{C}$ values obtained using the 2 fractionation methods were in close agreement. Both approaches resulted in light fractions with $\mathrm{C} / \mathrm{N}$ ratios of $\sim 30$. The light fraction of the sonicated Shaver sample had a higher $\mathrm{C} / \mathrm{N}$ ratio than that of the shaken sample, but the difference falls within 1 standard error of the mean (determined by Gaussian error propagation) of laboratory replicates. The light fractions of the sonicated soils had slightly lower ${ }^{14} \mathrm{C}$ values than those of the shaken soils $\left(\Delta \Delta^{14} \mathrm{C} \sim 12 \%\right.$ for Musick and $\sim 14 \%$ o for Shaver).

The heavy fractions of the sonicated samples had $\mathrm{C} / \mathrm{N}$ ratios of $\sim 12$, whereas the heavy fractions of the shaken samples had $\mathrm{C} / \mathrm{N}$ ratios of $\sim 20$-very close to the bulk soil $\mathrm{C} / \mathrm{N}$ values (Table 6 ). Sonication was associated with the dissolution of $12 \pm 8 \%$ of the whole soil carbon for Musick and $19 \pm$ $5 \%$ of the whole soil carbon for Shaver. Mass balance calculations indicate that the dissolved fraction had relatively high $\mathrm{C} / \mathrm{N}$ ratios (53 for Musick and 26 for Shaver) and depleted $\Delta^{14} \mathrm{C}$ values. The difference between the $\Delta^{14} \mathrm{C}$ values of the heavy fraction and dissolved fraction was substantially greater in the case of Musick $\left(\Delta \Delta^{14} \mathrm{C} \sim-72 \%\right.$ ) than in the case of Shaver $\left(\Delta \Delta^{14} \mathrm{C} \sim-10 \%\right.$ ). This generally agrees with the observation that for the Musick soil, the heavy fraction obtained after sonication is ${ }^{14} \mathrm{C}$-enriched relative to that obtained after shaking $\left(\Delta \Delta{ }^{14} \mathrm{C}=32 \%\right.$ ), while the reverse is true for Shaver $\left(\Delta \Delta^{14} \mathrm{C}=-28 \%\right.$ ) (Table 6). 


\section{Charcoal}

We found that charcoal was unevenly distributed in the initial splits of the Shaver soil: One of the $0-1 \mathrm{~g} \mathrm{~cm}^{-3}$ replicates had a $\mathrm{C} / \mathrm{N}$ ratio of 52 (Table 5), and the ${ }^{14} \mathrm{C}$ of the heavy fraction obtained with the density/hydrolysis method was higher than the ${ }^{14} \mathrm{C}$ of the bulk sample (Table 6).

\section{DISCUSSION}

\section{Effects of Root Removal}

The size and ${ }^{14} \mathrm{C}$-derived turnover times of the Musick root fraction $(7 \%$ of the light fraction carbon and $\sim 11 \mathrm{yr}$, respectively) are comparable to those obtained by Gaudinski et al. (2000), who carefully quantified root dynamics in eastern US hardwood forest soils. Differences between the ${ }^{14} \mathrm{C}$ values of the Musick and Shaver root fractions illustrate that this fraction can have highly variable dynamics, however. Our results suggest that the modest root-removal effort increased the ${ }^{14} \mathrm{C}$-derived turnover times of the Musick and Shaver light fractions by $\sim 12 \%$ (equivalent to $\sim 6 \mathrm{yr}$ for Musick and $\sim 11 \mathrm{yr}$ for Shaver). Assuming this is a robust methodological effect (i.e. validated by more soils and replication), it is on par with measurable environmental effects such as a $1{ }^{\circ} \mathrm{C}$ increase in mean annual temperature (as deduced from Trumbore et al. 1996).

\section{Effect of Sonication}

We used sonication to disaggregate minerals so they could be separated according to differences in specific gravity. Sonication releases organic matter from the mineral matrix and the ionic strength of the SPT solution promotes its dissolution. Sonication may have led to a slight increase in the ${ }^{14} \mathrm{C}$ derived average age of the light fractions, an effect that would be due to liberation of mineral-protected carbon from inside aggregates (likely for the Musick soil) or loosely bound to minerals. Dissolution of organic matter in the SPT solution led to a marked decrease in the $\mathrm{C} / \mathrm{N}$ of the heavy fractions (Table 6), an effect that supports the notion that N-rich compounds form the most stable organomineral bonds (Sollins et al. 2006; Kleber et al. 2007).

We recovered $41-59 \%$ bulk $\mathrm{C}$ in the light fraction of our sonicated samples. In comparable California coniferous forest soil samples, Rasmussen et al. (2005) recovered $\sim 40 \%$ bulk $\mathrm{C}$ in the $<1.65 \mathrm{~g} / \mathrm{cc}$ fractions prior to sonication $\left(1500 \mathrm{~J} \mathrm{~g} \mathrm{soil}^{-1}\right)$, but $\sim 60 \%$ bulk $\mathrm{C}$ in the $<1.65 \mathrm{~g} / \mathrm{cc}$ fractions following sonication. The proportion of $\mathrm{C}$ recovered in the light fraction is highly variable (see reviews by Sollins et al. [2006] and Basile-Doelsch et al. [2007]). For example, Baisden et al. (2002) recovered $21-56 \%$ bulk $\mathrm{C}$ in the $<1.85 \mathrm{~g} / \mathrm{cc}$ fraction of sonicated A horizon California grassland soils, while Sollins et al. (1983) recovered between $28-63 \%$ bulk $C$ in the $<1.65 \mathrm{~g} / \mathrm{cc}$ fraction of 0 $30 \mathrm{~cm}$ unsonicated soil samples from a mudflow chronosequence in northern California from which roots had been removed.

Christensen (1992) reported that $1000 \mathrm{~J}$ of sonication energy per $\mathrm{g}$ of soil solution caused $25 \%$ of the soil carbon to be transferred from the silt fraction to the clay fraction. Using ultrasonic dispersion energy of $400 \mathrm{~J}$ per $\mathrm{g}$ of solution, Shang and Tiessen (2001) noted that carbon losses increase with the density of the SPT solution to a maximum of $10 \%$ of the total soil carbon at their highest density $\left(2.4 \mathrm{~g} \mathrm{~cm}^{-3}\right)$. Following the method of Baisden et al. (2002), we sonicated between each density separation, applying a total of $\sim 1300 \mathrm{~J}$ of ultrasonic dispersion energy per $\mathrm{g}$ of soil solution. This treatment successfully segregated mineral phases, but solubilized $17-26 \%$ of the bulk carbon in the SPT solution (Table 5). The amount dissolved is higher than the $\sim 11 \%$ loss reported by Baisden et al. (2002), yet similar to the 17-28\% reported by Crow et al. (2007), who did not sonicate the soils but allowed them to separate gravimetrically (by standing for $\sim 4$ days in a low-density SPT solution). 
The organic matter losses reported by Crow et al. (2007) had $\mathrm{C} / \mathrm{N}$ ratios that were similar to their bulk soils (but lower than their light fraction). Our results follow this trend for Shaver, but not for Musick (with a dissolved fraction $\mathrm{C} / \mathrm{N}$ ratio $\sim 53$ ). In addition, our ${ }^{14} \mathrm{C}$ results indicate that the lost fractions correspond to relatively old carbon, especially for Musick. In the Musick soil, where Fe and $\mathrm{Al}$ oxides promote moderate degrees of aggregation, the dissolved material probably corresponded to a mixture of colloidal particles (smaller than the 0.2 um diameter used to determine centrifugation/settling time according to Stoke's law) and intra-aggregate and oxyhydroxide bound organic matter that passed through the quartz fiber filters (e.g. Golchin et al. 1997). In the coarsetextured and weakly aggregated Shaver soil, OM losses may be more directly related to the ability of the acidic SPT solution to solubilize organic substances.

\section{Chemical Versus Density Separation of the Heavy Fraction}

The acid/base hydrolysis isolated a distinctly old carbon pool, which we failed to obtain by density alone. The only sonication/density fractions with enough carbon to account for this carbon pool are the $2-2.5 \mathrm{~g} \mathrm{~cm}^{-3}$ secondary mineral fractions, which, due to their high ${ }^{14} \mathrm{C}$ values $\left(\Delta^{14} \mathrm{C}_{(2-2.5} \mathrm{g} \mathrm{cm}^{-3}\right)-$ $\Delta{ }^{14} \mathrm{C}_{\text {(residue) }}=+106 \%$ o for Musick and $+131 \%$ o for Shaver), are inferred to contain a mix of old and young carbon. Additionally, despite distinct levels of organic matter associated with the 2-2.2 and $2-2.5 \mathrm{~g} \mathrm{~cm}^{-3}$ fractions, their ${ }^{14} \mathrm{C}$ values were indistinguishable. This corresponds with observations by both Baisden et al. (2002) and Jastrow (2003), who found distinct density fractions associated with similar turnover times, and suggests that fast and slow cycling carbon pools are intimately associated (Swanston et al. 2005), either because sites available for organic matter sorption on mineral surfaces are not saturated (Oades 1995) or because organic molecules are arranged onto minerals via tightly bound stable inner layers as well as loosely bound dynamic outer layers (Kleber et al. 2007).

According to the X-ray diffraction data, the acid/base residue fraction is made up of quartz, hornblende, and anorthite. The ${ }^{14} \mathrm{C}$ values in the density-separated quartz $\left(2.6-2.7 \mathrm{~g} \mathrm{~cm}^{-3}\right)$, hornblende $\left(>3.2 \mathrm{~g} \mathrm{~cm}^{-3}\right)$, or feldspar-dominated $\left(2.5-2.6 \mathrm{~g} \mathrm{~cm}^{-3}\right)$ fractions are, however, too high to match those of the acid/base residue. Therefore, it appears that the acid/base residue fraction contains chemically recalcitrant organic matter from throughout the soil mass, rather than organic matter protected by chemically resistant minerals, as has sometimes been assumed. One reason for very low ${ }^{14} \mathrm{C}$ values in the acid/base residue is that acid/base hydrolysis dissolves $\mathrm{Fe}$ and $\mathrm{Al}$ oxyhydroxides, which tend to layer onto kaolin surfaces (Sposito 1989) and in A horizons tend to complex fairly recent organic matter (Masiello et al. 2004). Dissolving this layer of higher-turnover organomineral (oxide) associations would leave behind the smaller proportion of organic matter that adheres directly to the kaolin surfaces.

The ${ }^{14} \mathrm{C}$ values associated with kaolins, feldspars, and micas were distinct in the Musick soil, but not in the Shaver soil. This may be a function of differences in the nature of the mineral surfaces or in the nature of the organic matter and its ability to sorb to mineral particles. Compared to the Shaver soil, the Musick soil may, for example, have more Fe and/or Al oxyhydroxide kaolin coatings associated with young carbon. In the Shaver soil, intense leaching at snowmelt rapidly transforms micas into vermiculite, which has much greater specific surface area (Douglas 1989; Dahlgren et al. 1997), but may not sequester organic matter for as long as the Musick's long-lived micas, which can intercalate organic matter for extended periods of time. 


\section{SUMMARY AND CONCLUSIONS}

The low-density fraction can be quite heterogeneous and include contributions from different kinds of organic material from roots, with relatively fast turnover, to charcoal, which can persist for millennia. Because the ${ }^{14} \mathrm{C}$ of the root fraction can be quite different from the rest of the low-density fraction, roots should be separated before calculating the turnover time of the remaining light fraction. The effect of our simple, operationally defined live+dead root removal was comparable to that based on quantitative live root removal; this indicates that such an effort can help to quantify soil organic matter dynamics when removal of the live root (non-soil component) is not feasible. Time lags associated with roots and leaf litter inputs will also directly affect the ${ }^{14} \mathrm{C}$-derived dynamics of the low-density fraction. Therefore, researchers need to make sure they describe how the sample is treated and what assumptions are used in estimating turnover time.

The degree to which sonication augments the light fraction or promotes the dissolution of organic matter in the SPT solution depends in part on the amount of organic matter trapped in soil aggregates and weakly bound to minerals and in part on the details of the methodology. In this study, sonication had a minor effect on the ${ }^{14} \mathrm{C}$ value and $\mathrm{C} / \mathrm{N}$ of the light fraction, but promoted the solubilization of a substantial portion of the soil organic matter in the SPT solution and led to dramatic reductions in the total $\mathrm{C}, \mathrm{C} / \mathrm{N}$, and ${ }^{14} \mathrm{C}$ values of the heavy fractions.

Sonication enabled the separation of unique mineral classes along a continuum of increasing density. This approach may thus be useful in detailed assessments of intact organomineral phases. The various minerals were not, however, associated with unique carbon pools; none of the mineral fractions corresponded to a carbon pool that was both as old and as large as the acid/base residue. Overall, the density/hydrolysis fractionations (Trumbore protocol) isolated soil fractions with more distinct ${ }^{14} \mathrm{C}$ signatures than the sonication/density fractionations (Basile protocol). Combining data from both fractionation approaches and X-ray diffraction, we learned that in these soils the turnover rate of the slowest cycling carbon is governed by chemical recalcitrance of the organic matter, not by the nature of the minerals with which it is associated.

\section{ACKNOWLEDGMENTS}

This research was undertaken as part of CC's doctoral dissertation and primarily funded by a Kearney Foundation of Soil Science grant to ST. RA's participation was funded by the California Agricultural Experiment Station. The $2002{ }^{14} \mathrm{C}$ measurements were funded by a grant to Amundson from the Center for Accelerator Mass Spectrometry at the Lawrence Livermore National Laboratory. We thank R Wenk and T Teague at the Department of Earth and Planetary Science at UC Berkeley for facilitating the X-ray diffraction analyses; A Blum at the USGS in Menlo Park, California, for help in designing a low-background holder for small XRD samples; A Thompson in the Silver Lab at UC Berkeley for help with the $\mathrm{C} / \mathrm{N}$ analyzer; P Brooks and S Mambelli at the Center for Stable Isotope Biogeochemistry at UC Berkeley for their assistance with the mass spectrometer; and M Kashgarian and P Zermeño at LLNL for assistance with ${ }^{14} \mathrm{C}$ AMS measurements. We are indebted to 2 anonymous reviewers whose comments greatly improved this paper.

\section{REFERENCES}

Amundson R, Stern L, Baisden T, Wang Y. 1998. The isotopic composition of soil and soil-respired $\mathrm{CO}_{2}$. Geoderma 82(1-3):83-114.

Baisden WT, Amundson R, Cook AC, Brenner DL. 2002. Turnover and storage of $\mathrm{C}$ and $\mathrm{N}$ in five density fractions from California annual grassland surface soils. Global Biogeochemical Cycles 16(4):1117, doi: 10.1029/2001GB001822.

Balesdent J. 1987. The turnover of soil organic fractions estimated by radiocarbon dating. The Science of the Total Environment 62:405-8.

Basile-Doelsch I, Amundson R, Stone WEE, Borschneck 
D, Bottero JY, Moustier S, Masin F, Colin F. 2007. Mineral control of carbon pools in a volcanic soil horizon. Geoderma 137(3-4):477-89.

Boutton TW. 1991. Stable carbon isotope ratios of natural materials: I. Sample preparation and mass spectrometric analysis. In: Coleman DC, Fry B, editors. Carbon Isotope Techniques. New York: Academic Press. p 155-71.

Brindley GW, Brown G, editors. 1984. Crystal Structures of Clay Minerals and Their X-ray Diffraction Identification. London: Mineralogical Society. 495 p.

Christensen BT. 1992. Physical fractionation of soil and organic matter in primary particle size and density separates. Advances in Soil Science 20:1-90.

Crow SE, Swanston CW, Lajtha K, Brooks JR, Keirstead H. 2007. Density fractionation of forest soils: methodological questions and interpretation of incubation results and turnover time in an ecosystem context. Biogeochemistry 85(1):69-90.

Dahlgren RA, Boettinger JL, Huntington GL, Amundson RG. 1997. Soil development along an elevational transect in the western Sierra Nevada, California. Geoderma 78(3-4):207-36.

Douglas LA. 1989. Vermiculites. In: Dixon JB, Weed SB, editors. Minerals in Soil Environments. Madison: Soil Science Society of America. p 635-68.

Ewing SA, Sanderman J, Baisden WT, Wang Y, Amundson R. 2006. Role of large-scale soil structure in organic carbon turnover: evidence from California grassland soils. Journal of Geophysical Research 111: G03012, doi:10.1029/2006JG000174.

Gaudinski JB, Trumbore SE, Davidson EA, Zheng S. 2000 . Soil carbon cycling in a temperate forest: radiocarbon-based estimates of residence times, sequestration rates and partitioning of fluxes. Biogeochemistry 51(1):33-69.

Gaudinski JB, Trumbore S, Davidson E, Cook A, Markewitz D, Richter D. 2001. The age of fine-root carbon in three forests of the eastern United States measured by radiocarbon. Oecologia 129(3):420-9.

Goh KM, Stout JD, O'Brien BJ. 1984. The significance of fractionation in dating the age and turnover of soil organic matter. New Zealand Journal of Science 27(1):69-72.

Golchin A, Oades JM, Skjemstad JO, Clarke P. 1994. Study of free and occluded particulate organic matter in soils by solid state ${ }^{13} \mathrm{C} \mathrm{CP/MAS} \mathrm{NMR} \mathrm{spectroscopy}$ and scanning electron microscopy. Australian Journal of Soil Research 32(2):285-309.

Golchin A, Baldock JA, Clarke P, Higashi T, Oades JM. 1997. The effects of vegetation and burning on the chemical composition of soil organic matter of a volcanic ash soil as shown by ${ }^{13} \mathrm{C}$ NMR spectroscopy. II. Density fractions. Geoderma 76(3-4):175-92.

Greenland DJ, Ford GW. 1964. Separation of partially humified organic materials from soils by ultrasonic dispersion. In: 8th International Congress of Soil Science Transactions. Bucharest, Romania. p 137-48.
Jastrow JD. 2003. Mean residence time of soil carbon pools: controlling factors and implications for soil carbon cycling. Ecological Society of America Annual Meeting Abstracts 88:166-7.

Jenkinson DS, Andrew SPS, Lynch JM, Goss MJ, Tinker PB. 1990. The turnover of organic carbon and nitrogen in soil. Philosophical Transactions of the Royal Society B Biological Sciences 329(1255):361-8.

Kleber M, Sollins P, Sutton R. 2007. A conceptual model of organo-mineral interactions in soils: self-assembly of organic molecular fragments into zonal structures on mineral surfaces. Biogeochemistry 85(1):9-24.

Krull ES, Swanston CW, Skjemstad JO, McGowan JA. 2006. Importance of charcoal in determining the age and chemistry of organic carbon in surface soils. Journal of Geophysical Research 111: G04001, doi: 10.1029/2006JG000194.

Levin I, Hesshaimer V. 2000. Radiocarbon-a unique tracer of the global carbon cycle dynamics. Radiocar bon 42(1):69-80.

Masiello CA, Chadwick OA, Southon J, Torn MS, Harden JW. 2004. Weathering controls on mechanisms of carbon storage in grassland soils. Global Biogeochemical Cycles 18: GB4023, doi: 10.1029/ 2004 GB002219.

Minagawa M, Winter DA, Kaplan IR. 1984. Comparison of Kjeldahl and combustion methods for measurement of nitrogen isotope ratios in organic matter. Analytical Chemistry 56(11):1859-61.

Monnier G, Turc L, Jeanson-Luusinang C. 1962. Une methode de fractionnement densimetrique par centrifugation des mateires organiques du sol. Annales Agronomiques 13(1):55-63. In French.

Nelson DW, Sommers LE. 1996. Carbon and organic matter. In: Sparks DL, editor. Methods of Soil Analysis. Part 3: Chemical Methods. Soil Science Society of America, Book Series 5. Madison: Soil Science Society of America. p 961-1010.

Oades JM. 1995. An overview of processes affecting the cycling of organic carbon in soils. In: Zepp RG, Sonntag C, editors. The Role of Nonliving Organic Matter in the Earth's Carbon Cycle. New York: John Wiley and Sons Ltd. p 293-303.

O'Brien BJ, Stout JD. 1978. Movement and turnover of soil organic matter as indicated by carbon isotope measurements. Soil Biology and Biochemistry 10(4): 309-17.

Olk DC, Gregorich EG. 2006. Overview of the Symposium Proceedings, "Meaningful Pools in Determining Soil Carbon and Nitrogen Dynamics." Soil Science Society of America Journal 70(3):967-74.

Parton WJ, Schimel DS, Cole CV, Ojima DS. 1987. Analysis of factors controlling soil organic matter levels in Great Plains grasslands. Soil Science Society of America Journal 51(5):1173-9.

Paul EA, Collins HP, Leavitt SW. 2001. Dynamics of resistant soil carbon of Midwestern agricultural soils measured by naturally occurring ${ }^{14} \mathrm{C}$ abundance. $\mathrm{GeO}$ - 
derma 104(3-4):239-56.

Paul EA, Morris SJ, Conant RT, Plante AF. 2006. Does the acid hydrolysis-incubation method measure meaningful soil organic carbon pools? Soil Science Society of America Journal 70(3):1023-35.

Rasmussen C, Torn MS, Southard RJ. 2005. Mineral assemblage and aggregates control carbon dynamics in a California conifer forest. Soil Science Society of America Journal 69(6):1711-21.

Rodhe H. 1992. Modeling biogeochemical cycles. In: Butcher SS, Charlson RJ, Orians GH, Wolfe GV, editors. Global Biogeochemical Cycles. San Diego: Academic Press. p 55-72.

Schoeneberger PJ, Wysocki DA, Benham EC, Broderson WD. 1998. Field Book for Describing and Sampling Soils. Natural Resources Conservation Service, USDA. Lincoln: National Soil Survey Center.

Shang C, Tiessen H. 1998. Organic matter stabilization in two semiarid tropical soils: size, density, and magnetic separations. Soil Science Society of America Journal 62(5):1247-57.

Shang C, Tiessen H. 2001. Sequential versus parallel density fractionation of silt-sized organomineral complexes of tropical soils using metatungstate. Soil Biology and Biochemistry 33(2):259-62.

Six J, Merckx R, Kimpe K, Paustian K, Elliott ET. 2000. A re-evaluation of the enriched labile soil organic matter fraction. European Journal of Soil Science 51(2): 283-93.

Six J, Guggenberger G, Paustian K, Haumaier L, Elliott ET, Zech W. 2001. Sources and composition of soil organic matter fractions between and within soil aggregates. European Journal of Soil Science 52(4):60718.

Sollins P, Spycher G, Topik C. 1983. Processes of soil organic matter accretion at a mud flow chronosequence Mt. Shasta, California. Ecology 64(5):1273-82.

Sollins P, Swanston C, Kleber M, Filley T, Kramer M, Crow S, Caldwell BA, Lajtha K, Bowden R. 2006. Organic $\mathrm{C}$ and $\mathrm{N}$ stabilization in a forest soil: evidence from sequential density fractionation. Soil Biology and Biochemistry 38(11):3313-24.

Sposito G. 1989. The Chemistry of Soils. New York: Oxford University Press. 304 p.

Stuiver M, Polach HA. 1977. Discussion: reporting of ${ }^{14} \mathrm{C}$ data. Radiocarbon 19(3):355-63.

Swanston CW, Torn MS, Hanson PJ, Southon JR, Garten CT, Hanlon EM, Ganio L. 2005. Initial characterization of processes of soil carbon stabilization using forest stand-level radiocarbon enrichment. Geoderma 128(1-2):52-62.

Swift RS. 1996. Organic matter characterization. In: Sparks DL, editor. Methods of Soil Analysis. Part 3: Chemical Methods. Soil Science Society of America, Book Series 5. Madison: Soil Science Society of America. p 1011-69.

Torn MS, Lapenis AG Timofeev A, Fischer ML, Babikov BV, Harden JW. 2002. Organic carbon and carbon isotopes in modern and 100-year-old-soil archives of the Russian steppe. Global Change Biology 8(10):941-53.

Trumbore SE. 1988. Carbon cycling and gas exchange in soils [PhD dissertation]. New York: Columbia University. $194 \mathrm{p}$.

Trumbore SE. 2000. Age of soil organic matter and soil respiration: radiocarbon constraints on belowground C dynamics. Ecological Applications 10(2):399-411.

Trumbore SE, Zheng S. 1996. Comparison of fractionation methods for soil organic matter ${ }^{14} \mathrm{C}$ analysis. $R a$ diocarbon 38(2):219-29.

Trumbore SE, Vogel JS, Southon JR. 1989. AMS ${ }^{14} \mathrm{C}$ measurements of fractionated soil organic matter: an approach to deciphering the soil carbon cycle. Radiocarbon 31(3):644-54.

Trumbore SE, Chadwick OA, Amundson R. 1996. Rapid exchange between soil carbon and atmospheric carbon dioxide driven by temperature change. Science 272(5260):393-6.

Wang Y, Hsieh Y-P. 2002. Uncertainties and novel prospects in the study of the soil carbon dynamics. Chemosphere 49(8):791-804. 